Revue d'histoire de l'Amérique française

REVUE D.HISTOIRE DE L'AMÉRIQUE FRANÇAISE

\title{
TESSIER (abbé Albert), Canadiennes (Collection Radio-Collège). Éditions Fides Montréal 1946, 160 pages
}

\section{Antoine Bernard}

Volume 1, numéro 3, décembre 1947

URI : https://id.erudit.org/iderudit/801400ar

DOI : https://doi.org/10.7202/801400ar

Aller au sommaire du numéro

Éditeur(s)

Institut d'histoire de l'Amérique française

ISSN

0035-2357 (imprimé)

1492-1383 (numérique)

Découvrir la revue

Citer ce compte rendu

Bernard, A. (1947). Compte rendu de [TESSIER (abbé Albert), Canadiennes (Collection Radio-Collège). Éditions Fides Montréal 1946, 160 pages]. Revue d'histoire de l'Amérique française, 1(3), 445-446.

https://doi.org/10.7202/801400ar d'utilisation que vous pouvez consulter en ligne.

https://apropos.erudit.org/fr/usagers/politique-dutilisation/ 
TESSIER (abbé Albert), Canadiennes (Collection Radio-Collège). Éditions Fides Montréal 1946, 160 pages.

Le titre est déjà un éloge. Il veut souligner le courage, le cran, les qualités d'adaptation de celles qui furent nos mères canadiennes, aux premiers jours de la Nouvelle-France et jusqu'au XIXe siècle. Il invite le lecteur, peut-être surtout la lectrice, à s'arrêter un instant, au milieu du tourbillon de la vie moderne, pour contempler cette vision de paix, cette atmosphère de chrétienne et française hardiesse que nous offre l'histoire des premières familles établies dans la vallée laurentienne.

L'auteur s'adresse aux Canadiennes d'aujourd'hui. Il les sait distraites, entraînés à droite et à gauche par beaucoup de préoccupations, sans compter les divertissements dont parlait Pascal. Qu'importe! M. Tessier, toujours optimiste, a foi aux sentiments les meilleurs de la femme chrétienne, de la jeune fille de chez nous. Et il leur tient ce langage.

* Evoquez avec tendresse les émouvantes silhouettes des femmes venues de France vers nos terres sauvages. Voyez leurs visages clairs, sereins, un peu tendus par la fatigue et l'angoisse; étudiez leurs yeux expressifs, instinctivement aux aguets, troublés par l'inconnu inquiétant qui se dresse de tous côtés comme une menace. Imaginez-les d'abord, ces femmes, dans le vide immense de la mer, sur les ponts balayés par les embruns, ou plus souvent dans les entreponts obscurs et fétides... Elles souffrent de la faim, des tiraillements du mal de mer, des cauchemars de la fièvre... Elles vont quand même, têtues, calmes, décidées à se rendre jusqu'au bout de l'horizon, par delà les bancs de brouillard et les ondulations éternelles de l'eau... Toute notre histoire porte leur empreinte souveraine. " (page 156)

Pourquoi ce retour sur le passé? C'est que la leçon du passé peut raffermir le présent et préparer un meilleur avenir. " Nous resterons un peuple digne de respect dans la mesure où la femme continuera chez nous sa mission séculaire... Il y a présentement dans les écoles et couvents près de 400,000 fillettes et jeunes filles. Que ceux qui rédigent, contrôlent ou appliquent les programmes scolaires, se souviennent de la tâche formidable que la vie imposera à cette armée féminine. On ne prépare 
pas aux grands devoirs de la vie uniquement avec du savoir cérébral. Le savoir n'est pas l'élément principal de la culture, ni de l'éducation... " (page 159)

Ce livre de vulgarisation (dans le meilleur sens du mot) contient donc plus qu'une instructive leçon d'histoire du Canada. Il s'adresse surtout à des jeunes filles qui vont passer de l'atmosphère transitoire et un peu tiède du pensionnat ou de la classe, au grand air de la vie. En vue de faciliter la transition, l'auteur fait appel d l'imagination, à l'intelligence, à la sensibilité de sa lectrice étudiante, sans oublier que le livre peut aussi être lu avec profit par l'éducatrice elle-même. Le tout forme a la fois un beau livre et une bonne action. Un index très utile s'ajoute aux 160 pages de texte. Il contient quelque cent soixante noms de "Canadiennes ". 